\title{
Research on the Security Issues and Countermeasures of the Network Payment in Art E-commerce
}

\author{
Yanli Li \\ Yunnan Arts University, No.1577 Yuhua Road,Chenggong District,Kunming 650500,Yunnan \\ Province,P.R.China \\ lyledu@qq.com
}

Keywords: Art E-commerce; Network Payment; Security Issues; Countermeasures

\begin{abstract}
Starting from the era background of Art Internet, this paper expounds the connotation and characteristics of the network payment in artwork trade, introduces the network payment mode and payment tools, puts forward the security issues faced by network payment, as well as provides the security countermeasures for network payment from the three aspects of technical standard, legislative level regulation and industries supervision, which offers a reference opinion to lead and promote the rapid and healthy development of art e-commerce in china.
\end{abstract}

\section{Introduction}

With the further development of the Internet+ idea and its economic form, China's E-commerce industry has possessed a more profound theoretical and practical basis, and which is gradually subdivided into the concept of art Internet. The development and popularization of the artwork online trading makes the E-commerce plays a more and more important role in the field of artwork trading, the network payment means adopted by artwork online trading also gradually entered the sights of traders and researchers. According to the statistics data from iResearch, 2015Q2, the transaction amount of China's third-party Internet payment reached 2.81365 trillion yuan, attaining a year-on-year growth of $52.9 \%$ and a ring growth of $15.7 \%$. The fine tuning of competition patterns in Internet payment of the third-party makes the payment enterprises meet a more and more fierce competition. While, the problems faced by network payment and the countermeasures to be taken have become the important research direction of the researchers. How to solve the security issues in the payment process of art E-commerce, establish and perfect the environment for the secure network payment of China's art E-commerce, is the key to promote the rapid and healthy development of China's art E-commerce.

\section{Connotation and Characteristics of the Network Payment}

\section{Connotation of Network Payment System.}

Network payment refers to the currency payment or fund flow via network, carried out by the electronic trading parties, including consumers, manufacturers and financial institutions, through using the method of Secure Electronic Payment. Which mainly includes electronic money, electronic credit card and electronic check.

The evolution process of payment means is: payment method in primitive society--bartering, payment method in natural social economy -- paper currency, payment method in the era of industrial economy-- payment and settlement system with bank as intermediary (credit currency), and payment method in the era of network economy-- electronic currency.

Formation of network payment system.

The network payment system mainly consists of customers, merchants, bank network, payment gateways, CA certificate centers and so on.

(1) Customers: Selecting goods online, and then entering into the electronic payment link after the confirmation of orders. Customers should possess electronic payment tools.

(2) Merchants: Receivers of electronic payment. Merchants should have the accounts of each bank, they can build a payment platform of their own or rent the third-party payment platform. 
(3) Bank network: Private network of banks for communication and data processing.eg. China National Financial Network.

(4) Payment gateway: Security interface between public Internet platform and bank private network.

(5) CA certificate center: which is the notarization institution of the third-party, access and regulator of the E-commerce market, whose role is similar to the industrial and commercial bureau.

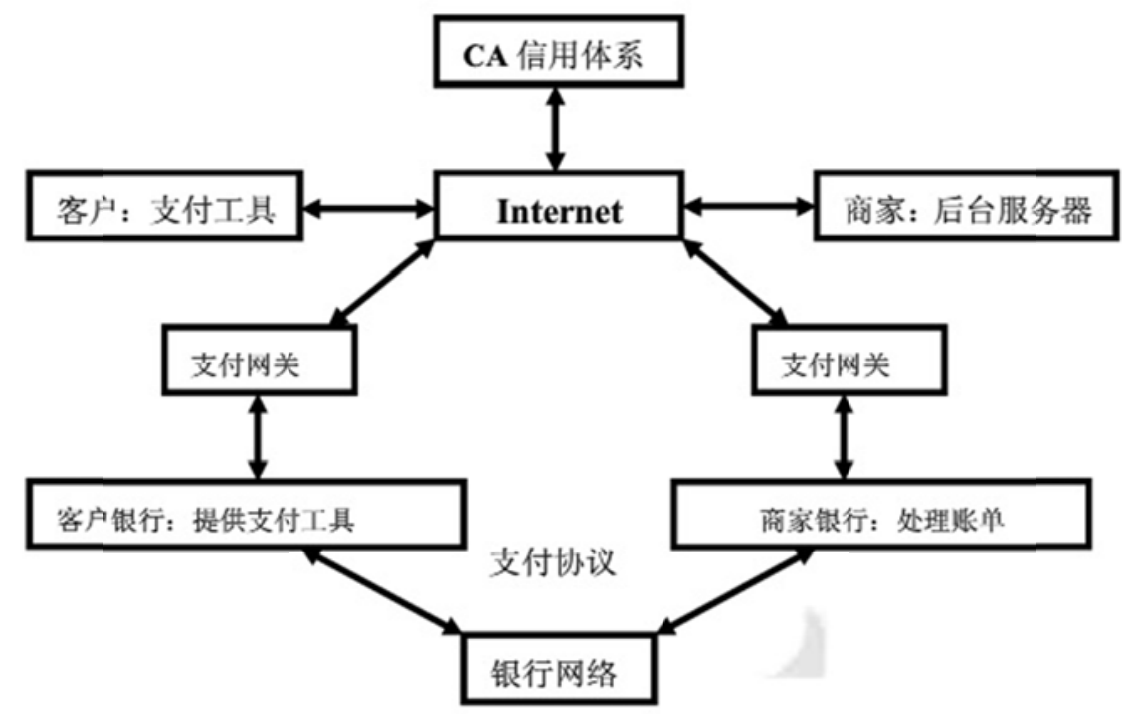

Figure 1. Basic structure of the network payment system

\section{Characteristics of Network Payment.}

(1) By using advanced technologies, network payment completes the information transmission through the digit transfer, all kinds of its payment methods adopt digital means to finish the payments; while the traditional way of payment finishes the payments via the transfer of physical entities, such as the cash flow, the notes circulation and the exchange of the bank, etc.

(2) The environment for network payment is based on an open system platform (i.e., the Internet); while the traditional payment runs in a relatively closed system.

(3) Network payment adopts the most advanced means of communication, such as the Internet, while the traditional payment uses the traditional communication medium. Network payment has a very high requirement for software and hardware facilities, the network-connected computers, the related software and other ancillary facilities are necessary; while the requirement of the traditional payment is relatively low.

(4) Network payment has the advantages of convenient, fast, efficient and economic, etc. Without going outside, users can finish the whole payment process only with an Internet enabled PC or even a mobile phone in a very short time. The payment cost is just equivalent to one of dozens, even one of hundreds of the traditional payment.

(5) There are still some problems need to be solved in network payment, security issues are the key. Such as the prevention of hacker intrusion, internal crime and passwords leak and some other issues related to the safety of funds.

\section{Network Payment Modes and Payment Tools}

\section{Internet Banking.}

The Internet banking also known as network banking or online banking, it refers to the banks which provide the traditional service items to customers through Internet, the service items, based on the Internet technology, include account opening, query, account reconciliation, internal-bank transfer, cross-bank transfer, credit, online securities, investment and financing, etc. So, without going outside, customers can safely and conveniently manage their current and fixed time deposits, checks, credit cards and personal investments, etc. So to speak, Internet banking is a virtual bank counter on the Internet. 
The Internet banking is also called "3A bank"', because it is not subject to the constraints of time and space, and can provide financial services to customers at anytime, anywhere and in anyway.

\section{Payment Platform of the Third Party.}

The network payment exists the problems of trade credit and the small scale websites can't afford the costs of technique, construction and maintenance, which is necessary for whom to interface with a number of commercial banks. Thus the third-party payment model is proposed. The third-party payment institutions are the new payment and settlement organizations emerged in recent years, it is a legal entity that provides the exchange and calculation of electronic payment instructions for the banking financial institutions or other institutions and individuals, in essence, it refers to the third-party payment providers offer exchange and settlement of electronic cash and other services for the two trading parties.

At present, the third-party payment has developed into the mainstream applications of network payment, eBay business is the support of PayPal internationally (founded in 2005, entered into China in 1998, the payment mechanism based on credit card, 2000 yuan as security of trading claims), at home, the AliPay, supported by Alibaba business, has developed to a certain scale and already carried out the transaction services of network payment more in depth. In the third-party payment mode, the payers must open accounts on the platform of the third-party payment institutions and provide them the information of credit cards or accounts. Recharging the account, transferring the virtual funds of this account to the beneficiary's account via the payment platform, then the payment is completed. The beneficiary can exchange the funds in the account to deposits of bank entity when needed. Throughout the payment chain, the third-party payment plays a role of connecting the bank with the two parties of purchaser and seller, and provides justice and arbitration services to both sides of the transaction.

\section{Security issues faced by network payment}

\section{Technical level.}

At present, the protocols, used both at home and abroad, for ensuring the safety of E-commerce payment system include SSL (Secure Socket Layer) and SET (Secure Electronic Transaction), etc. Here we mainly discuss the SSL.

Because the SSL protocol is simple to realize and independent of the application layer protocol, at the same time, it has been internally installed by most browsers and Web servers, so it is convenient to be applied in the network payment, its application is shown in Figure 2. In the transaction, clients (consumers) send the purchasers' information to the merchants firstly, and the merchants transmit the information to the bank, after the banks verify the validity of customers' information, they will inform the merchants finished the payment successfully, then the merchants notify consumers purchase successfully in the end. The credit card payment system of the international famous CyberCash supports this simple encryption mode. IBM and other companies also provide payment system based on this simple encryption mode.

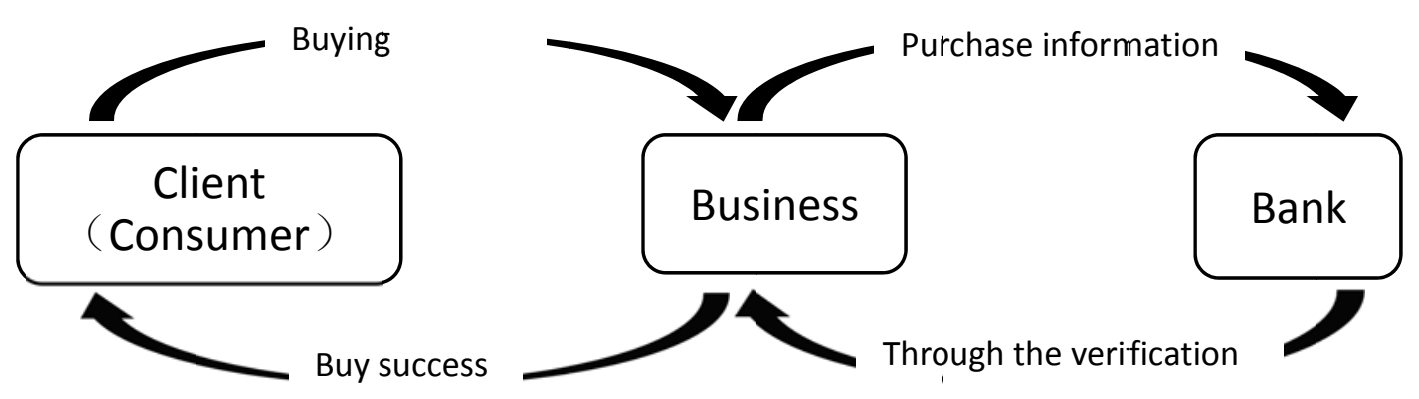

Figure 2. Schematic diagram of SSL protocol 
So we can see the SSL-based shopping process is relatively simple, it can establish a secure communication channel between the client and server only through the connection set up by a "handshake" process, to ensure the mutual exchange of data safely in the future. The browsers of Netscape and Microsoft as well as other companies all support SSL, so there are no special requirements for the clients, and the security services provided by SSL are transparent to the end-users.

\section{Legal Level.}

Although the china's art market has achieved a rapid development, it has always been in a state of disorder. The corresponding laws and regulations have not been perfected. The existing laws and regulations are simple and need to be improved in many places.

(1) The calibers of the legislative objects are not unified

For instance, for the "fine arts", "cultural artwork", "cultural relic artwork" and other concepts, both their connotations and extensions are not unified. This is a basic but very important issue.

(2) The lagging legislation about the trading method of art E-commerce

China's art trading has always existed the phenomena that behaviors before law and law can't restrain behaviors, which is particularly obvious in art E-commerce or other new ways of trading. The data shows, art exchanges were set up all over china, and the new trading practices, such as property right transaction about art share and so on, were also introduced. Where, the positive factors have not given a legal recognition in time. Currently, this trading model can only regulated by the documents of regulatory policies, which is issued by the State Council as well as the ministries and commissions. In fact, this specification is equivalent to a confinement for the art trading market, and even now the confinement has not been canceled.

\section{Management Level.}

(1) The lagging external supervision

The rapid development of China's E-commerce has caused the current widespread problem of lagging external supervision, and the industry segmentation makes all walks of life don't have a perfect supervision system of E-commerce. The disordered management, lagging supervision and other issues, all those factors in management Level greatly affect the sound operation of art E-commerce.

(2) Imperfect of the social credit system

Credit is the passport of market economy. In China, the market economy is not perfect, although it has achieved an economic boom, the construction of the corresponding social credit system is still lagging behind. As the punishment mechanism is not perfect, resulting in the low cost of default, the phenomenon of "dishonesty" often occurs, so there is no time to delay to establish a perfect social credit system.

\section{Research on the Security Supervision and Countermeasures of Network Payment}

\section{Technical standards need to make new breakthroughs.}

Because SSL is not specially designed for the art E-commerce, there must be some defects when it is applied on the network payment. From the services provided by the SSL protocol and its transaction process we can see, the operation of SSL protocol is based on the merchants' promise for keeping secret about the consumers' information, the confidentiality of information is determined by merchants, which is conducive to the merchants but not the consumers. In the primary stage of E-commerce, as the enterprises which apply E-commerce are mostly big companies with high reputation, so this problem has not been fully exposed. But with the development of E-commerce, many small and medium-sized companies are also involved, especially in the transactions of art E-commerce which often involve a larger payment amount, thus the problem of single authentication in the process of network payment become more and more prominent. Although the both sides authentication from the browser and Web server can be achieved through digital signatures and digital certificates in SSL3.0, there are still some problems with SSL protocol, which not only needs a professional repair and improvement from the technical level, but also needs to break through the current technical bottlenecks and establish the new 
technical standards.

Legislative supervision needs to be further strengthened.

There is a famous saying in the field of E-commerce: all the network problems are legal issues. Today is the heyday of the concept "Internet + art", art E-commerce has already become a common way of art transactions, but the lack of laws and regulations in art E-commerce has gradually become one of the bottlenecks for the development of China's art E-commerce. In the meantime of the art trading market and trading mechanisms are designed scientifically and operated in standardization, the legislative consciousness about art E-commerce needs to be further strengthened, the legislative hierarchy of art E-commerce should be further improved, the calibers of the legislative objects must be unified, and a perfect architecture of laws and regulations for art E-commerce, with a clear directionality, should be established to realize restraining and punishing the behaviors according to law, which should be the original intention of the legal supervision on art E-commerce. The international organizations should fully exert their leading roles to establish a legislation pattern that the government and non-government organizations supplement and promote each other mutually, make clear the basic idea on the secure transaction of art E-commerce, attach importance to the role of experts and establish the legislative idea that the specialized follows the comprehensive.

\section{Refinement of industry management, perfection of the social credit system.}

The management for the industries of art E-commerce is a systematic project, the principle of the complete technical neutrality should be insisted, the roles of the government and industry organizations in the secure supervision of art E-commerce should be defined, pay attention to connecting with the international society, and attach importance to the protection of the network privacy.

In addition to the routine management, the industries' credit records need to be improved constantly and the construction of industries credit should be promoted; under the premise of strict supervision, system perfection and the protection of information security, opening up the credit service market gradually and steadily and introducing the advanced management experience and technology from abroad; preventing the illegal acquisition and misuse of credit information, promoting the healthy development of the social credit system and the credit service market. Meanwhile, along with the development of the market economy and the change of government functions, the autonomy assistant function of the industrial organizations should be fully exerted.

\section{Conclusion}

With the idea of big data was proposed and the continuous evolution of "Internet +concept" in art trading market, the art E-commerce has developed rapidly. While providing convenience and opportunity for the majority of users, the art E-commerce, which depends on the method of network payment, is also facing one of the biggest challenges, that is the security of transactions, it can be said that the solution to the security of transactions is the core for the smooth and healthy development of China's art E-commerce. This paper mainly expounds the connotation and characteristics of the network payment in artwork trade, introduces the network payment mode and payment tools, puts forward the security issues faced by network payment, in order to lead and promote the rapid and healthy development of art E-commerce in china, the researchers should make breakthroughs in technical standards constantly, conduct a comprehensive supervision from the legislative level, establish a more perfect system for industries management, and gradually set up a safety supervision mode of E-commerce on this basis. Only in this way, the road of China's art E-commerce will be wider, and the new economic form of "Internet + art" can always operate as a normal state.

\section{Acknowledgement}

Fund Project: Scientific research fund of education department, Yunnan province. Project Name: 《Research on the Network Security of Art E-commerce in New Media Context $》$. Project Number: 
2015 Y347.

\section{References}

[1] Efraim Turban.Electronic Commerce-A Managerial Perspective (Third Edition).Beijing: Higher Education Press,2006.

[2] Wankang Li. General Introduction of Art Marketing. Shanghai: Fudan University Press,2005.

[3] Zhiwen Cai. Security of E-commerce. Beijing: Peking University Press,2013.

[4] Fuping Gao. Research Report on E-commerce legislation. Beijing: Law Press China, 2004.

[5] Xiaoling Guo. Research on the Supervision System of E-commerce Security. Anhui University,2007. 